\section{ESTRATEGIAS DE EFICIENCIA EN LA CONSERVACIÓN DE LO CONSTRUIDO EN LOS ESPACIOS NATURALES PROTEGIDOS. LA EXPERIENCIA DE DOÑANA}

\author{
José María Rincón Calderón \\ Universidad de Sevilla \\ ORCID iD: http://orcid.org/0000-0002-7426-3810 \\ josrincal@alum.us.es \\ Carmen Galán Marín \\ Universidad de Sevilla \\ ORCID iD: http://orcid.org/0000-0003-1929-3280 \\ cgalan@us.es \\ Domingo Sánchez Fuentes \\ Universidad de Sevilla \\ ORCID iD: http://orcid.org/0000-0001-8405-6906 \\ dsanchez@us.es
}

Cómo citar este artículo/Citation: Rincón Calderón, J. M., Galán Marín, C. y Sánchez Fuentes, D. (2017). Estrategias de eficiencia en la conservación de lo construido en los espacios naturales protegidos. La experiencia de Doñana. Arbor, 193 (786): a424. doi: http://dx.doi.org/10.3989/arbor.2017.786n4012

Recibido: 13 julio 2016. Aceptado: 28 diciembre 2016.

RESUMEN: Es notable la cantidad de edificaciones que han existido y existen en Doñana. Estas construcciones, muy diversas, exponen la identidad del lugar. Han desaparecido algunas de ellas; otras se hallan en un proceso de degradación que nos hace plantearnos la cuestión de la conservación de lo construido en un medio natural singular. En el presente trabajo, se recopila, actualiza y completa la información disponible sobre el estado actual del patrimonio edificado de Doñana y se analiza la estructura de implantación de las edificaciones. Se comprueba cómo ha evolucionado la edificación en el Parque a lo largo de la historia, en qué estado ha llegado hasta nuestros días, cómo ha servido al hombre de este entorno, de qué manera ha desempeñado sus funciones básicas de cobijo y protección del hombre y cómo podrían afrontar su futuro, en torno a las mismas estrategias de eficiencia que las han hecho sobrevivir hasta hoy.

PALABRAS CLAVE: Doñana; parques naturales; arquitectura vernácula; eficiencia; conservación; Patrimonio de la Humanidad.

\section{EFFICIENCY STRATEGIES IN BUILDING CONSERVATION IN NATURAL PROTECTED AREAS. THE EXPERIENCE OF DOÑANA}

Copyright: (C) 2017 CSIC. Este es un artículo de acceso abierto distribuido bajo los términos de la licencia Creative Commons Attribution (CC BY) España 3.0.

ABSTRACT: It is remarkable the amount of buildings that have existed and still exist in Doñana. These constructions, which are very diverse, are examples of the local identity. Some have been lost, but others are in a process of degradation that raises the question of building conservation in a unique natural environment. In this paper, the available information on the current state of the Doñana built heritage is compiled, updated and completed. The geographical distribution structure of the buildings' locations is also analyzed. This study verifies how these buildings have evolved throughout the park history to the condition we see now, how they have been useful to their inhabitants in this environment, how they have performed their roles of sheltering and protecting men, and how they could face the future using the same strategies they have developed to survive until our day.

KEYWORDS: Doñana; natural parks; vernacular architecture; efficiency; conservation; World Heritage. 


\section{INTRODUCCIÓN}

\subsection{El hombre y la naturaleza en los extremos}

La relación entre el hombre y la naturaleza en los espacios naturales protegidos no transita por lugares comunes, ni sigue las pautas habituales y más extendidas en el mundo contemporáneo. Frente al hombre post Revolución Industrial, que entra como una fuerza modificadora de la naturaleza y mantiene una relación de equilibrio inestable y precario con el medio que le rodea, el hombre que ha habitado históricamente estos lugares, incluso el habitante contemporáneo, mantiene una relación mucho más compleja con estos medios naturales. Un primer acercamiento al estado actual de estos espacios puede dejarse llevar por una aproximación maniquea y una simplificación propia de determinados prejuicios, y contemplar a la naturaleza como una fuerza positiva y al hombre como un motor negativo. Esto no es válido en la mayor parte de los espacios naturales protegidos; la naturaleza es aquí una naturaleza experimentada y vivida por el hombre, con una densa historia común (Castrillo Díaz, 2000, p. 14). (Figura 1)

El imaginario colectivo no asocia los espacios naturales protegidos a la edificación y, sin embargo, es notable la cantidad de edificaciones que han existido y siguen existiendo hoy en algunos de ellos. La mayoría de ellas son reflejo de los aprovechamientos históricos de estas tierras: caza, pesca, ganadería, aprovechamientos forestales. Y es notable también la presencia de una arquitectura popular y vernácula doméstica, como la más cercana al hecho fundacional de la arquitectura: dar cobijo frente al medio (Agudo Torrico, 1999, pp. 13-15). La vivienda, como manifestación más funcional de esta necesidad de arquitectu- ra, es también testimonio de rasgos diferenciadores y de la construcción de una cultura local. La edificación es aquí testigo y huella de una relación singular entre hombre y naturaleza.

En este marco el territorio de Doñana, con su conocida riqueza natural y su historia azarosa, es paradigma de cómo el hombre y un trozo de tierra (no un trozo cualquiera) han trenzado sus recorridos y sus historias. La historia de Doñana no se entiende sin el paso del hombre por ella. La historia de los hombres que vivieron y viven hoy en Doñana no se comprende si no se penetra en la compleja relación que mantienen con este medio natural y de la que son testigos los edificios y construcciones que han ido salpicando este territorio desde hace siglos y que han ayudado al hombre en la colonización de estas tierras.

\subsection{El patrimonio edificado en Doñana como huella y valor}

Las investigaciones sobre las edificaciones en Doñana han quedado casi siempre en un segundo plano en la actividad científica desplegada con especial intensidad desde hace 50 años alrededor del Parque Nacional. Una visión, quizás reduccionista, ha tendido a limitar sus valores patrimoniales a sus valores biológicos; hoy en día, esa visión está superada con la incorporación a las valoraciones patrimoniales de otro tipo de cuestiones culturales, sociales, etnológicas, etc., y se reconoce a las edificaciones su valor como exponentes de estos valores. Para algunas de las edificaciones de este entorno este reconocimiento llega tarde, ya que se encuentran en estados de conservación que las hacen irrecuperables. Otras se hallan actualmente en un proceso de degradación física y funcional que nos lleva a plantearnos

Figura 1. Paisajes de Doñana. Bosque, marisma, dunas

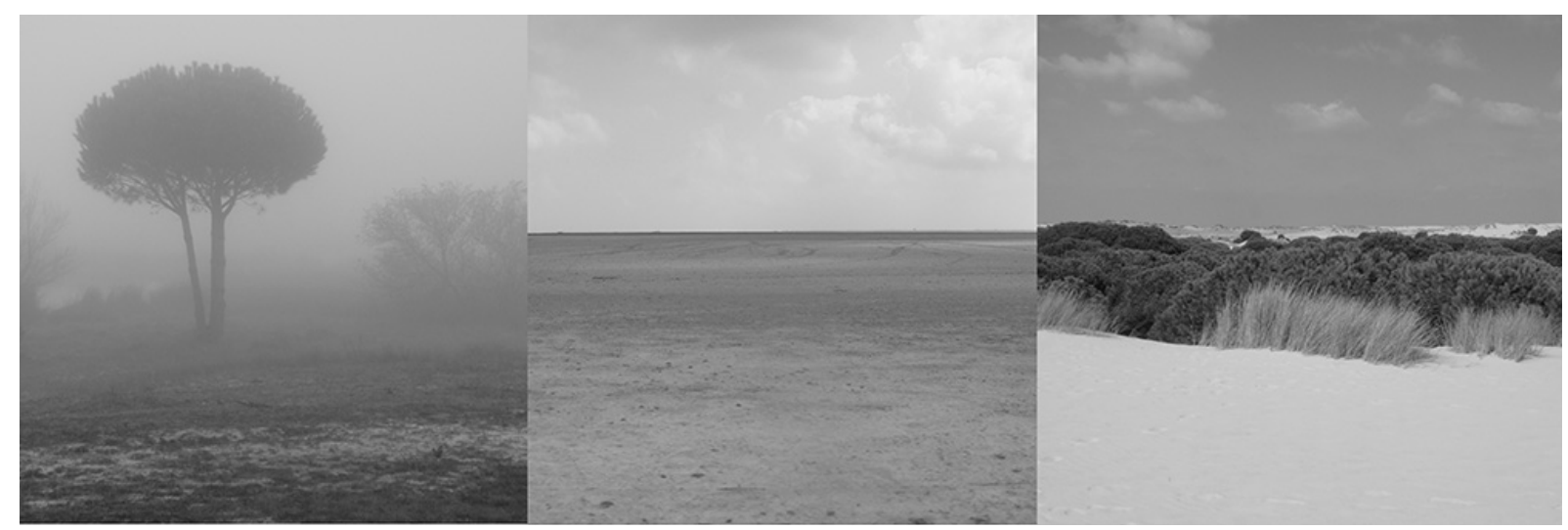

Fuente: elaboración propia. 
cómo resolver la cuestión de la conservación de lo construido en un medio natural tan singular. Estas inquietudes nos obligan a valorar la situación actual y a analizar las posibilidades de pervivencia de estos edificios en un futuro inmediato.

El conjunto de edificios que se ubican en Doñana, con su diversidad de fechas de construcción y de estados de conservación, son testigos y huellas físicas de la relación entre sus habitantes y este particular medio físico. Su estudio puede ofrecer datos de esa relación y del recorrido histórico del ser humano en este territorio, de cómo ha adaptado sus modos de vida a una naturaleza tan presente y singular, y de la manera en que sus ecosistemas han influido en la configuración física del hábitat humano. Los sistemas constructivos, los usos y las formas de vida ligadas a estas edificaciones contribuyen a forjar la singularidad de estos territorios desde el momento en que son el apoyo necesario para el hombre en su proceso de habitación, explotación, domesticación e investigación en medios naturales de tanta potencia. (Figura 2)

\subsection{Doñana. El contexto. El laboratorio}

Doñana -como territorio limitado y acotado por diferentes figuras administrativas y de protección- se enclava en la parte más occidental de la Comunidad Autónoma de Andalucía, en el Sur de España, alrededor del antiguo estuario en la desembocadura del río Guadalquivir en el Océano Atlántico. Sus tierras se ubican en catorce municipios de tres provincias diferentes (Huelva, Sevilla y Cádiz). Su medio físico, en el que predominan los ecosistemas de marismas, cotos, arenas, dunas móviles y un extenso frente marítimo y fluvial, ha dificultado históricamente la formación de asentamientos y núcleos de población es- tables. La explotación de estas tierras (por la nobleza y posteriormente por la burguesía) para aprovechamientos marginales (caza, ganadería, pesca, madera, carbón, salinas, etc.) ha ido favoreciendo la aparición de pequeños asentamientos en zonas concretas, diseminados y aislados, que han transformado el medio físico más cercano de una manera casi imperceptible y con unos modos integrados en las dinámicas naturales. Estos asentamientos y sus edificaciones han modificado incluso el hábitat biológico en el que se insertan (Fernández Alés y Muñoz Reinoso, 2014). El interés científico por estas tierras -que comienza en el siglo XIX- y las figuras de protección ambiental se consolidan en 1963, con la creación de la Reserva Biológica de Doñana, y seis años más tarde con la creación del Parque Nacional de Doñana (Decreto 2412/1969), que actualmente abarca 54.254 ha., y con la Ley 91/1978 del Parque Nacional de Doñana. Por otra parte, en 1989 se declara el Parque Natural de Doñana (Ley 2/1989), figura que en la actualidad protege 53.835 ha. de este territorio. Ambos ámbitos de protección se integran en la gestión administrativa común que se produce desde el Espacio Natural Doñana (Ley 8/1999). (Figura 3)

Doñana -como territorio, como idea, como mitoabarca un ámbito que supera y desborda los límites de las figuras administrativas y de protección que sectorizan y contienen su territorio físico. El estudio que desarrolla el presente artículo se limita al ámbito del Parque Nacional, entorno en el que se encuentra una variedad de edificaciones, tipologías constructivas y unidades paisajísticas representativas de toda el área de Doñana. Todos los tipos edificatorios singulares en Doñana, en la medida en que están vinculados inexorablemente a su territorio y a su historia, están

Figura 2. Interiores de edificaciones. Casa Puntal de los González, Casa del Fahinao, Choza de la Plancha

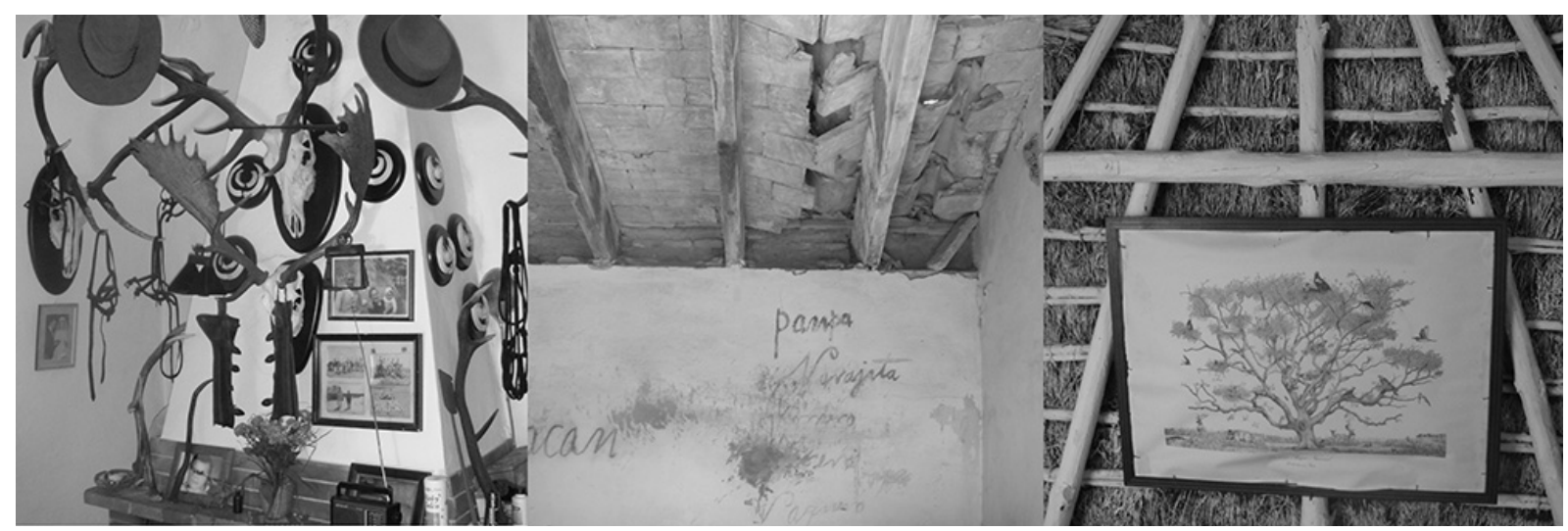

Fuente: elaboración propia. 
Figura 3. Situación de Doñana en la Península Ibérica

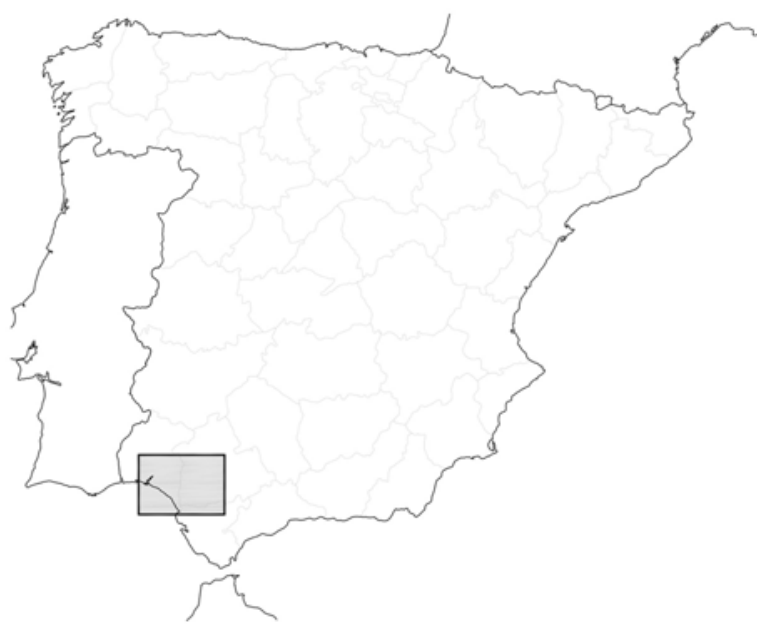

Fuente: elaboración propia.

presentes dentro de los límites administrativos del Parque Nacional, por lo que este se convierte en una suerte de laboratorio donde además las condiciones de contexto de estas edificaciones (administrativas, climáticas, de uso) se dan en grado extremo. Es, por tanto, el punto de partida idóneo para una investigación de este tipo.

La abundante presencia de edificación dentro de los límites del Parque Nacional también impone la necesidad de simplificar y limitar el objeto de estudio. Aunque se harán algunas referencias a los palacios (fundamentales en su capacidad de ser polos de atracción del poblamiento y en su conexión con el uso cinegético predominante en un largo periodo de la historia de Doñana) y a otras edificaciones, la investigación se centra en la arquitectura residencial (de manera temporal o permanente) que, como se comprobará, ha mantenido en parte su uso y lo ha adaptado a las nuevas circunstancias de vida actual del Parque.

El artículo se marca como objetivos principales el analizar la estructura de implantación territorial, temporal y funcional de las edificaciones. Se plantea igualmente la selección de casos de estudio de entre las construcciones del Parque, de manera que la representatividad de los mismos permita observar y analizar cuestiones extensibles al conjunto de las edificaciones de Doñana. Tras la caracterización objetiva de estos casos, la extrapolación de lo observado permitirá aportar argumentos al debate sobre la conservación de lo construido en un medio natural tan singular.

\section{LOS USOS, LAS TIPOLOGÍAS DE LA EDIFICACIÓN Y EL TERRITORIO}

La mayoría de las edificaciones que han ido poblando a lo largo de la historia el entorno de Doñana, aparecen ligadas a algunos de los aprovechamientos, a veces difíciles y extremos, que permiten estas tierras. Descartada la agricultura extensiva por el tipo de terrenos que constituyen la mayor parte del entorno, quedan la ganadería y otra serie de oficios menores en cantidad, pero importantes en tanto que revelan una relación muy particular del hombre con este medio natural. Se trata de trabajos que aprovechan lo que ofrece la naturaleza y se integran de una manera fluida en el ciclo, los climas y el paso de las estaciones en Doñana: la pesca, el aprovechamiento de la sal, de la madera, de las piñas, del carbón (Granados Corona y Ojeda Rivera, 1994, pp. 53-74). Por otra parte, ocupa un lugar muy singular el aprovechamiento cinegético que, como se ha indicado, ha sido actividad principal de un amplio periodo histórico de Doñana, y ha generado una cierta ocupación y la aparición de determinadas edificaciones.

De este modo, los distintos tipos edificatorios en Doñana surgen directamente ligados a los usos y a los aprovechamientos del suelo y de la naturaleza.

\subsection{Edificaciones singulares: palacios, torres almena- ras, cuarteles, edificaciones científicas, casas salineras}

Aunque esta investigación se centre en la edificación doméstica y de pequeño tamaño, no puede obviarse la importancia que han tenido determinadas tipologías en la relación entre el hombre y el territorio de Doñana. De este modo, los palacios surgen ligados al aprovechamiento cinegético de estas tierras, en un principio por parte de la realeza y la nobleza, y posteriormente por parte de la burguesía. Dentro de un plan trazado por Felipe II, consistente en jalonar toda la costa nacional de torres de vigilancia para custodia y defensa del territorio frente a las posibles invasiones desde África, surgen las torres almenara. En la misma línea de vigilancia, pero centradas en el contrabando de mercancías y bienes, las casas cuartel, que en principio fueron ocupadas por el cuerpo de carabineros y posteriormente por la Guardia Civil, han permanecido habitadas hasta la segunda mitad del siglo XX. Ligadas al aprovechamiento de la sal y a paisajes existentes en toda la Baja Andalucía, destaca el tipo de las casas salineras, de las que quedan en Doñana tres ejemplos, al borde del río Guadalquivir, en diferentes estados de ruina y abandono. Por último, debido al aumento del interés científico por Doñana en la década de los 50 y 
60 del siglo $\mathrm{XX}$, y fundamentalmente a la declaración de Parque Nacional en 1969, surgen una serie de edificaciones científicas, de apoyo a la labor investigadora.

Cada uno de estos conjuntos de edificaciones merece un estudio específico, dadas sus características tipológicas y sus singularidades patrimoniales. En la actualidad, muchos de estos edificios singulares se dedican a albergar usos científicos y de gestión del parque, además de al alojamiento eventual de invitados y personalidades. Otros son restos difícilmente visitables y abandonados a su suerte. (Figura 4)

\subsection{Los hatos}

El término hato puede proceder del término gótico fat, que significa 'vestidos', 'equipaje', 'bagaje', mezclado con el árabe hazz, que se refiere a 'porción que toca a cada cual', 'pago a un criado por su alimentación o sueldo' (Castrillo Díaz, 2000, p. 94). Este origen toponímico arroja pistas sobre la evolución a lo largo de la historia de Doñana del tipo edificatorio al que nos referimos hoy en día como "hato". Así, el hato pasa de ser en su origen un lugar de descanso de pastores, protegido con elementos efímeros como techumbres y sombrajos, a evolucionar hasta convertirse en chozas y, posteriormente, en edificaciones de fábrica.

Este tipo edificatorio está ineludiblemente ligado al uso ganadero, del que se tienen noticias en Doñana desde la Baja Edad Media, principalmente focalizado en la cría de ganado caballar, vacuno y lanar, y siempre localizados en torno a puntos donde existe agua. La evolución del régimen de tenencia y explotación del suelo en la historia de estas tierras ha influido decisivamente en la aparición de los hatos en determi- nados puntos de Doñana, en aquellos en los que era más viable la cría de ganado. Con la evolución de los usos del suelo, marcada de manera importante por la repoblación de pinares en la zona de Las Marismillas y posteriormente en todo el entorno (a partir de 1737), los ecosistemas ganaderos degeneran y la funcionalidad de los hatos va adaptándose a nuevos usos. También a partir de mediados del siglo XVIII, el uso cinegético está relacionado con este tipo edificatorio, ya que se comienza a dispersar a los guardas de los cazaderos por el territorio, y van alojándose en chozas y ventas que jalonan el mismo, hasta mediados del siglo XIX, fecha de la que se tiene constancia de las primeras edificaciones de fábrica de este tipo (Granados Corona y Ojeda Rivera, 1994, pp. 53-74). Es decisiva, asimismo, en el siglo XX la creación del Parque Nacional, que aprovecha estas edificaciones como casas de guarda y de apoyo en la labor de cuidado y vigilancia del territorio.

Desde el punto de vista formal, los hatos son un conjunto de estructuras más o menos efímeras y una edificación principal, todo ello alojado dentro de un cercado; así, se suelen encontrar alrededor de la edificación pequeños huertos, un pozo, un horno para pan, gallineros, abrevaderos para ganado, chamizos para resguardo del coche o perreras. Todo el conjunto suele estar ubicado bajo uno o más árboles de gran porte, como protección frente a las tormentas y los rayos. (Figura 5)

Los hatos que hoy en día están ocupados se dedican a usos de apoyo de la guardería del parque, alojamiento de los guardas y apoyo a las actividades científicas.

\subsection{Las chozas}




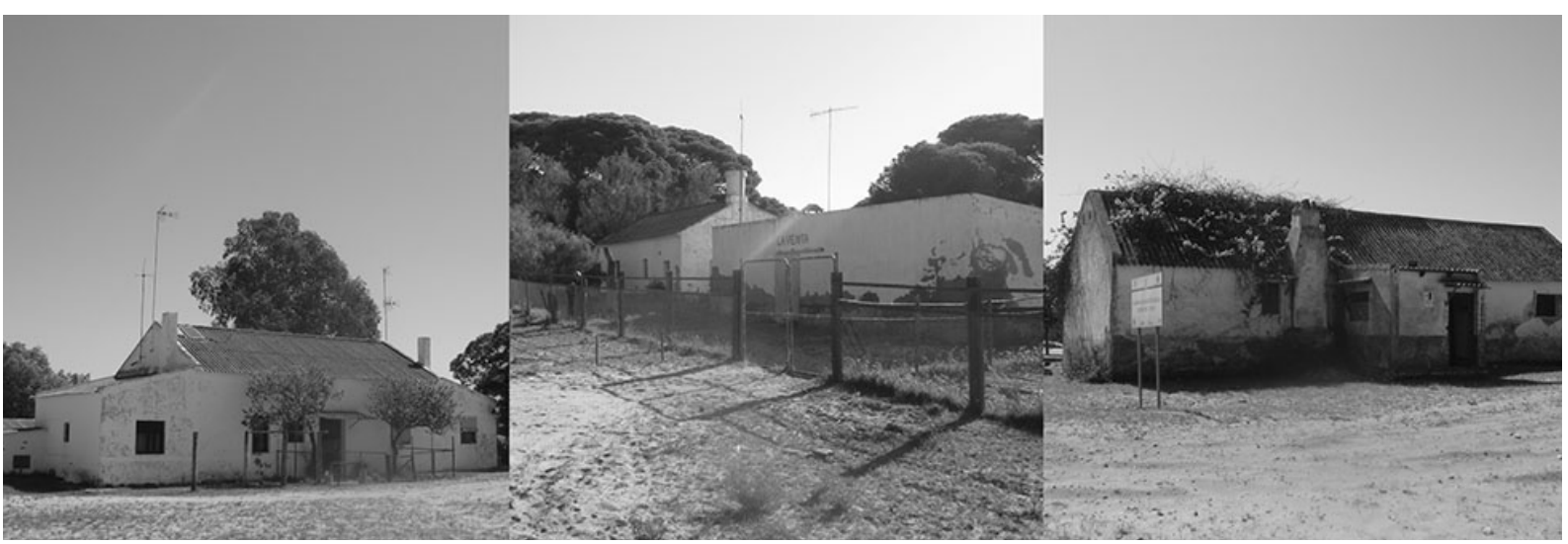

Fuente: elaboración propia.

Las chozas aparecen en su configuración actual, sin que pueda datarse claramente su origen, como evolución de tipos de construcción aún más primitivos, probablemente efímeros, ligados a algunos aprovechamientos estacionales. Existe la constatación de que a finales del siglo XIX hay gran número de familias que poseen derecho a cultivar en Doñana y a aprovechar algunas parcelas, por la tolerancia del propietario. Se trata de un grupo numeroso de población, formada principalmente por los parcelarios, los chamiceros y los carboneros, pero también por personas que aprovechaban la piña, la madera...y que transportaban todos estos bienes a los asentamientos urbanos, principalmente a Sanlúcar de Barrameda en el caso de los habitantes de las zonas de Pinar del Faro y los pinares de Las Marismillas (García de Alvear, 1986, p. 14). En el caso de las chozas situadas en la Marisma, su aparición puede tener más que ver con aprovechamientos ganaderos y de pesca, y están más ligadas territorialmente al municipio de Hinojos. Hay que señalar que las chozas no se dan únicamente en el ámbito rural de Doñana, sino que, en determinadas épocas de penuria económica, han sido frecuentes también en barrios de poblaciones cercanas como Isla Mayor, Villamanrique o Pilas (Cobo López y Tijera Jiménez, 2008) o en otras zonas rurales andaluzas. En 1969 se establece el Parque Nacional y se imponen limitaciones que afectan directamente en su modo de vida y en sus sistemas productivos a los habitantes de estas chozas. En los años 70, se produce una emigración masiva de la población que ocupa las chozas a poblaciones de los alrededores, por falta de trabajo.

La conceptualización de este tipo edificatorio es sencilla y parece surgir de una manera natural del propio medio, como las presas de los castores o los ni- dos de los pájaros. Las chozas se presentan en muchos casos como un accidente del propio terreno. A ello colabora indudablemente el material vegetal, de un color ocre que se vuelve parduzco con el tiempo, y su morfología orgánica. Normalmente, dos o más chozas se agrupaban en las llamadas casas de familia, dentro de un mismo cercado de brezo, o de hincos de sabina y alambre en la zona de la marisma (para evitar que lo tumbara el viento). Una de las chozas hacía las veces de cocina y las demás de estancia-dormitorios. No existen patrones formales, aunque sí constructivos, como se verá; no hay dimensiones estándar, ni huecos típicos, ni orientaciones preestablecidas. Lo habitual es que cada choza tenga dos puertas enfrentadas en sus lados principales, lo que permite una óptima ventilación cruzada; en las últimas chozas construidas, se incluyen más huecos, para disipar el humo en caso de incendios. Destaca el elemento de sombra del emparrado o la enramá, en la zona frontal y entre chozas, prolongación del espacio de estancia, zona de estar principal en verano y, según se constata en los casos que aún quedan en pie, elemento de gran calidad espacial. (Figura 6)

Hay constancia de chozas habitadas regularmente en el poblado de la Plancha hasta mediados de los años 80 del siglo XX. Desde entonces, las chozas que quedan en el Parque tienen un uso turístico, que es el caso de la mayoría de las chozas de la Plancha, o ganadero, como las chozas de la marisma.

La construcción de chozas, con la técnica tradicional que se ilustra más adelante con los casos estudiados, sigue siendo una actividad viva en Doñana, resultando además económicamente rentable para varias cuadrillas que se dedican actualmente a ello, que constru- 


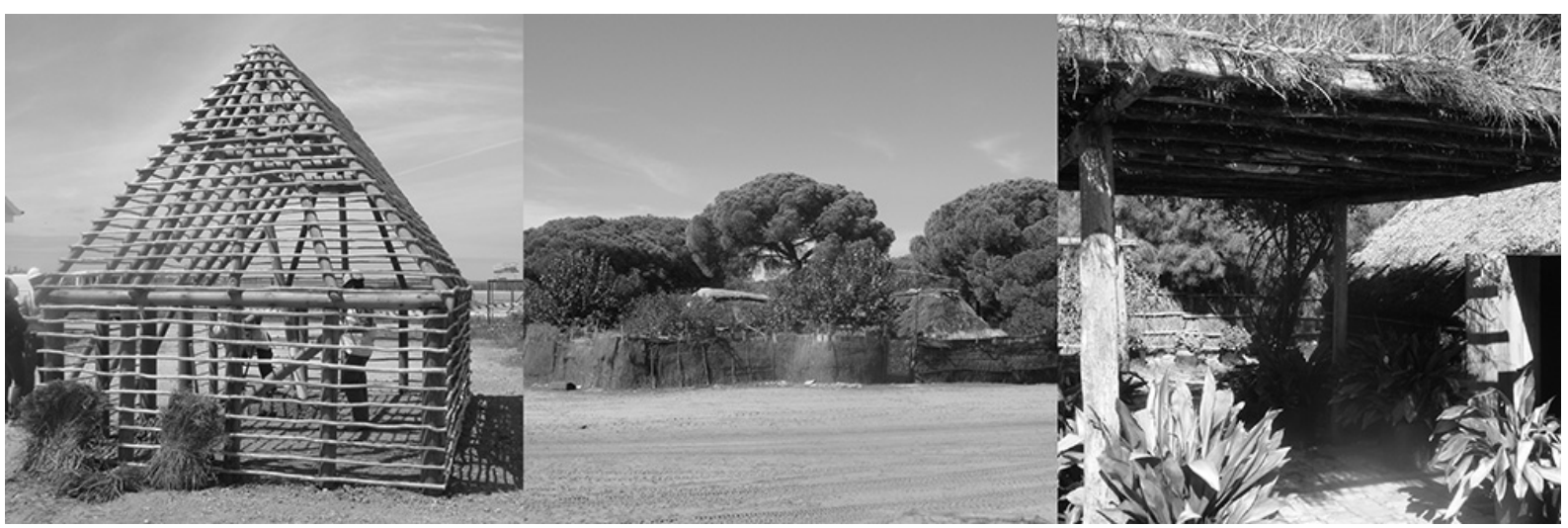

Fuente: elaboración propia.

yen chozas destinadas principalmente a uso público (observatorios de aves, centros de visitantes), recreativo (bares y chiringuitos en el entorno del Parque) y particular. Es importante también la existencia de una variante observada en numerosos casos de la zona, donde se construye la estructura y los cerramientos verticales con fábrica de ladrillo y la cubierta con la técnica tradicional de los choceros. Esto dota a estas edificaciones de un aire rústico y popular muy valorado en la zona. Cabe señalar que el proceso constructivo de las chozas actuales ha incorporado algunas técnicas contemporáneas, sobre todo en lo que respecta a las uniones de las maderas y al cosido de la capa vegetal, así como a la prevención de riesgos laborales, que se aplica en la actualidad como prescribe la legislación vigente. Igualmente se han observado en los ejemplos que se han podido examinar algunas variaciones del tipo -como las chozas de planta circular- así como variaciones en la estructura, consistentes sobre todo en la aparición de más rollizos y piezas de madera, con una función constructiva que probablemente sea redundante.

\subsection{La implantación en el territorio}

Como ya se ha comentado, Doñana no ha sido un lugar aprovechable para la agricultura intensiva, lo que probablemente haya provocado que en su territorio principal no se hayan producido grandes asentamientos. También ha influido la posesión de las tierras durante la mayor parte de su historia por parte de la nobleza y la burguesía. A estos hechos hay que unir la circunstancia de que Doñana es un territorio situado en un extremo geográfico, aislado, mal comunicado; por Doñana no "se pasa" para transitar hacia otro lugar, a Doñana "hay que ir" expresamente. De este modo, la edificación ha surgido de manera aislada, en puntos concretos o en muy pequeños asentamientos, siempre ligados al territorio y a los usos que de él se derivan, como se ha visto.

Si contemplamos un mapa mudo de Doñana, con todas las edificaciones representadas por puntos y una leyenda, no encontramos un patrón de distribución aparente que no sea la dispersión generalizada. Si añadimos sucesivamente las tipologías de la edificación, la red de los principales caminos, los límites de las unidades paisajísticas del Parque, y la caracterización de estas unidades paisajísticas, se pueden observar algunos datos interesantes. (Figura 7 y Figura 8)

La mayor concentración de edificaciones se produce en La Vera, en el borde de unión entre las marismas y las arenas estabilizadas. Este borde coincide también con el camino más importante de la red existente, el Camino de Sanlúcar, que une el Pinar del Faro con El Rocío. La mayor concentración de hatos históricamente se da en La Vera, el ecotono que une la marisma y la zona de bosques y matorrales, por la presencia indispensable para la actividad ganadera de agua y pastos $y$, de forma menor en número, en algunas zonas de agua periféricas, ricas igualmente en pastos (caso de la Casa de Santa Olalla o de la Casa de la Mogea). En la segunda mitad del siglo XIX, se edifican algunos hatos en la zona de Coto del Rey (Casa de la Pichiricha, Casa de la Cañada Mayor), aunque probablemente el origen de estos hatos esté más ligado a la actividad cinegética. Ya en la segunda mitad del siglo XX se siguen edificando hatos en zonas periféricas de la marisma y en algún otro punto disperso del Parque (Casa Brenes, Casa del Cherri, Casa Matías, Casa del Lobo, Casa de Mari López). En la década de los 80 del mismo siglo se da también un proceso a la inversa del habitual, con la demolición de al- 
Figura 7. Mapa de análisis de implantación territorial. Edificaciones, red de caminos y límites de unidades paisajísticas.

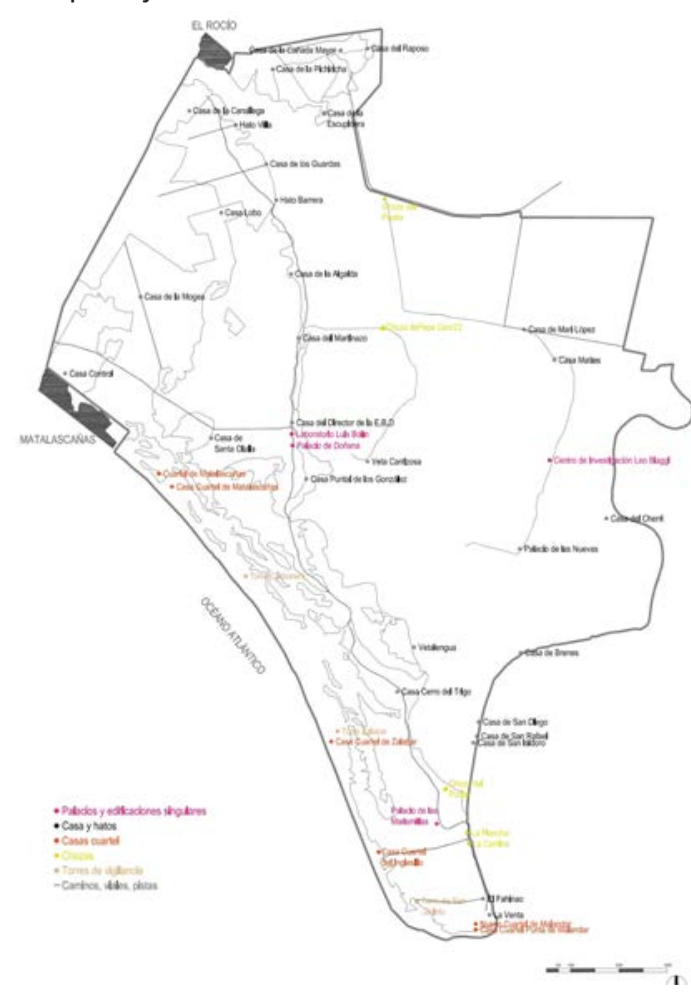

Fuente: elaboración propia.

gunos hatos en la zona de la marisma y la construcción en su lugar de chozas para alojar a grupos ganaderos de Almonte e Hinojos.

En la costa, como ya se ha explicado, se sitúan dos tipos concretos de edificaciones: las torres de vigilancia y las casas cuartel, estratégicamente emplazadas para un dominio de la visión de la costa y control del tráfico marítimo. Por otra parte, los hatos generan una red de caminos en la que estas edificaciones son los nodos. Si se representaran todos los caminos existentes, podría leerse el territorio con facilidad a través de los hatos. Como parece lógico, las marismas presentan una dispersión en sus puntos edificados, asentados normalmente en zonas donde el nivel de inundación no es máximo y se puede acceder con cierta facilidad en invierno. Se da aquí la presencia de algunos hatos y chozas de ganaderos, y el caso especial de las casas salineras, en el borde del Río Guadalquivir.

Los condicionantes del medio natural son claves para explicar los tipos edificatorios, dándose el hecho de que dentro de un mismo tipo se distinguen pequeñas variaciones dependiendo de en qué unidad pai-
Figura 8. Mapa de análisis de implantación territorial. Caracterización de las unidades paisajísticas

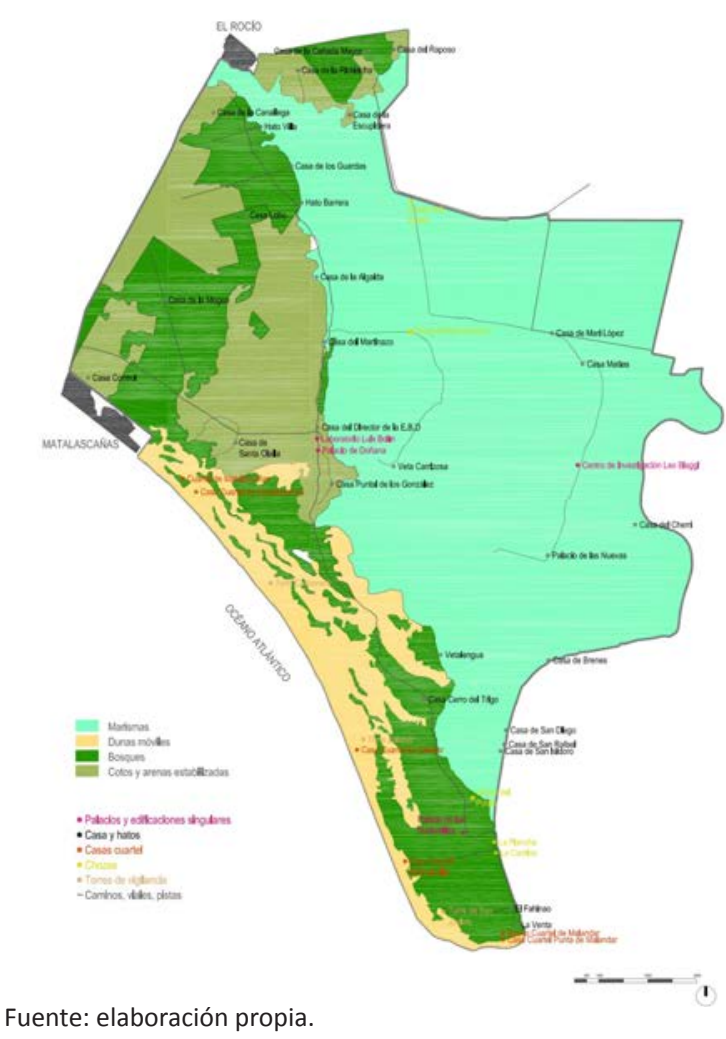

sajística esté situado, caso de los hatos y las chozas y de las diferencias tipológicas entre las situadas en marisma o en arenas estabilizadas.

\section{EL ESTADO ACTUAL DE LAS EDIFICACIONES RESI- DENCIALES DE PEQUEÑA ESCALA EN DOÑANA}

Para esta investigación ha sido necesario recopilar y actualizar la información sobre las edificaciones del Parque Nacional de una manera sistemática. Se lleva a cabo este propósito mediante la elaboración de un censo actualizado de las construcciones del Parque. Para ello, se ha partido de un estudio bibliográfico, centrado en la escasa bibliografía sobre el tema. Este estudio ha constituido un punto de partida básico para entrar en contacto con el patrimonio edificado del Parque; pero sus conclusiones y datos sobre muchas de las edificaciones han quedado superadas por el paso del tiempo, por los veloces cambios en Doñana y en los modos de vida de sus habitantes, y por el abandono de gran parte de los edificios. Han sido necesarias, por tanto, las investigaciones de campo para actualizar esta información. 
Por otra parte, se ha completado esta información con el estudio de los documentos urbanísticos siguientes, de carácter territorial y municipal, que inciden sobre el ámbito del Parque y contienen determinaciones sobre algunas de sus edificaciones, que se resumen a continuación:

a) Plan de Ordenación del Territorio del ámbito de Doñana (POTAD). En su memoria de ordenación, se encuentra un apartado destinado a la protección de los valores culturales y la identidad de Doñana, así como específicamente a "proteger las edificaciones rurales de interés representativas de Doñana que contribuyen a su identidad y a su cualificación territorial como exponentes de unas formas constructivas, tradiciones, modos de vida y uso productivo del territorio". En este marco, se señalan algunas edificaciones dentro del ámbito del presente trabajo, que se consideran "de interés": Núcleo de Marismillas, Palacio de Doñana, Casa Algaida, Casa Guardas, Casa de la Pichiricha y Casa de la Cañada Mayor. Esta selección puede considerarse escasa y en ella se perciben ausencias significativas. EI POTAD delega en el planeamiento de ámbito municipal la misión de establecer medidas de protección y conservación de este patrimonio.

b) Plan Rector de Uso y Gestión del Parque Natural de Doñana (PRUG). Este plan contiene un listado de las edificaciones existentes en el año 2004 en el Parque, con referencias a las fincas en las que cada una de ellas se encuentra, y con una escueta tabla en la que se ofrece información sobre el uso de cada edificación, el destino que se prevé para cada una, a modo orientativo, y algunas observaciones adicionales. Básicamente, se separan las edificaciones en tres grupos:

- Aquellas que se prevé mantener en su actual estado y uso. En este grupo hay algunos casos llamativos, como el Cuartel de Malandar, la Casa de Vetalengua, la Casa de los Guardas, Vetacarrizosa y la Casa del Cherri, cuyo estado se consideraba entonces aceptable y se preveía mantener para usos diversos. Hoy en día, todas estas edificaciones se encuentran sin uso y algunas de ellas en estado de ruina absoluta.

- Aquellas que se recomendaba rehabilitar, por considerarse de un valor patrimonial reconocible, y destinar a usos diversos. En este grupo también encontramos casos en los que no se han llevado a cabo estas intervenciones, como La Venta y la Casa del Cerro del Trigo.

- Aquellas que se proponía eliminar. En casi ningún caso se ha llevado a cabo la eliminación, aunque sí el abandono y la falta de uso, con el consiguiente proceso de degeneración de la edificación. En otros casos, sin embargo, en los que también se proponía la eliminación, se ha seguido manteniendo el uso e incluso la conservación, como en los casos de la Casa de Martinazo y de la Casa de Santa Olalla.

c) Revisión del Plan General de Ordenación Urbana de Almonte (RPGOU Almonte). Este documento urbanístico incluye en su catálogo un numeroso grupo de edificaciones dentro del Parque Nacional, abarcando la totalidad de los tipos edificatorios de Doñana. Sobre cada una de ellas, se plantean "propuestas para su protección" en diversos grados: desde las obras de conservación y mantenimiento hasta las obras de sustitución total con conservación tipológica, con varias posibilidades intermedias, con base en un análisis muy completo y en su valor patrimonial. Cabe señalar cómo varias de las edificaciones consideradas de interés en este catálogo se han abandonado y algunas de ellas se encuentran en ruina, como es el caso de la Casa de los Guardas, de Hato Barrera, de la Casa de Vetalengua, de la Casa del Cerro del Trigo o del Cuartel antiguo de Malandar.

d) Aprobación Inicial del Plan General de Ordenación Urbana de Hinojos (PGOU Hinojos). En este documento, que abarca un territorio del Parque con menor densidad de edificaciones, como es la Marisma de Hinojos, se protegen cuatro edificaciones: dos hatos y dos chozas. Todos ellos se engloban dentro de un mismo nivel de protección, el nivel B, Protección Estructural, que protege "los elementos que conforman las características básicas, tanto ornamentales como estructurales que definen la composición del edificio". Una de las edificaciones protegidas, la Choza de Pepe Caro, se encuentra en un precario estado de conservación.

A través de las visitas al Parque realizadas entre los meses de marzo de 2012 y mayo de 2013, se ha podido comprobar in situ el estado de determinadas edificaciones seleccionadas, pudiéndose documentar fotográfica y planimétricamente su situación, lo que se ha realizado de una manera más intensa en los casos finales elegidos para su estudio. De igual modo, se han mantenido algunas entrevistas con personas cualificadas en su relación con el Parque: técnicos del Espacio Natural, personal de guardería y habitantes de las propias edificaciones.

Como resultado del estudio bibliográfico y de las investigaciones de campo, se han elaborado unas tablas 
resumen de la edificación existente actualmente en el Parque, en las que se han cruzado todas las fuentes de datos existentes, con especial atención a las referencias bibliográficas más importantes, las determinaciones que sobre cada edificación dictamina el planeamiento territorial y el municipal, así como alguna información puntual sobre su estado actual, recogidas fundamentalmente en las entrevistas realizadas al personal de guardería. Igualmente se han reflejado en ellas su uso original y su uso actual.

Las tablas permiten establecer algunas consideraciones sobre el estado actual de conservación y el uso de las edificaciones en Doñana, que pueden ser útiles a la hora de plantear estrategias de conservación de este patrimonio. El poner en relación estas informaciones disponibles sobre cada edificación permite detectar situaciones llamativas, como algunos casos en los que el planeamiento prevé la demolición de una edificación concreta, que sin embargo continúa ocupada y en uso; o aquellos otros en los que el planeamiento protege determinadas edificaciones en diferente grado por sus valores patrimoniales y estas han desaparecido o han avanzado peligrosamente en su proceso de deterioro.

Por cuestiones de espacio, se presenta en este artículo un extracto de estas tablas, mostrando las edificaciones seleccionadas como casos de estudio. (La versión completa de estas tablas, se puede consultar en el Trabajo fin de Máster Las edificaciones de Doñana. Estrategias de eficiencia, de José María Rincón Calderón, codirigido por los doctores Carmen Galán Marín y Domingo Sánchez Fuentes en la Universidad de Sevilla). (Figura 9)

El censo de la edificación permite también comparar los estados de conservación, y establecer una primera categorización para de cada una de las construcciones estudiadas. A grandes trazos y con las limitaciones que este trabajo tiene de partida, se clasifican las 44 edificaciones en tres grados de conservación:

a) Dieciocho edificaciones se encuentran en uso y buen estado de conservación.

Figura 9. Extracto de censo de la edificación elaborado

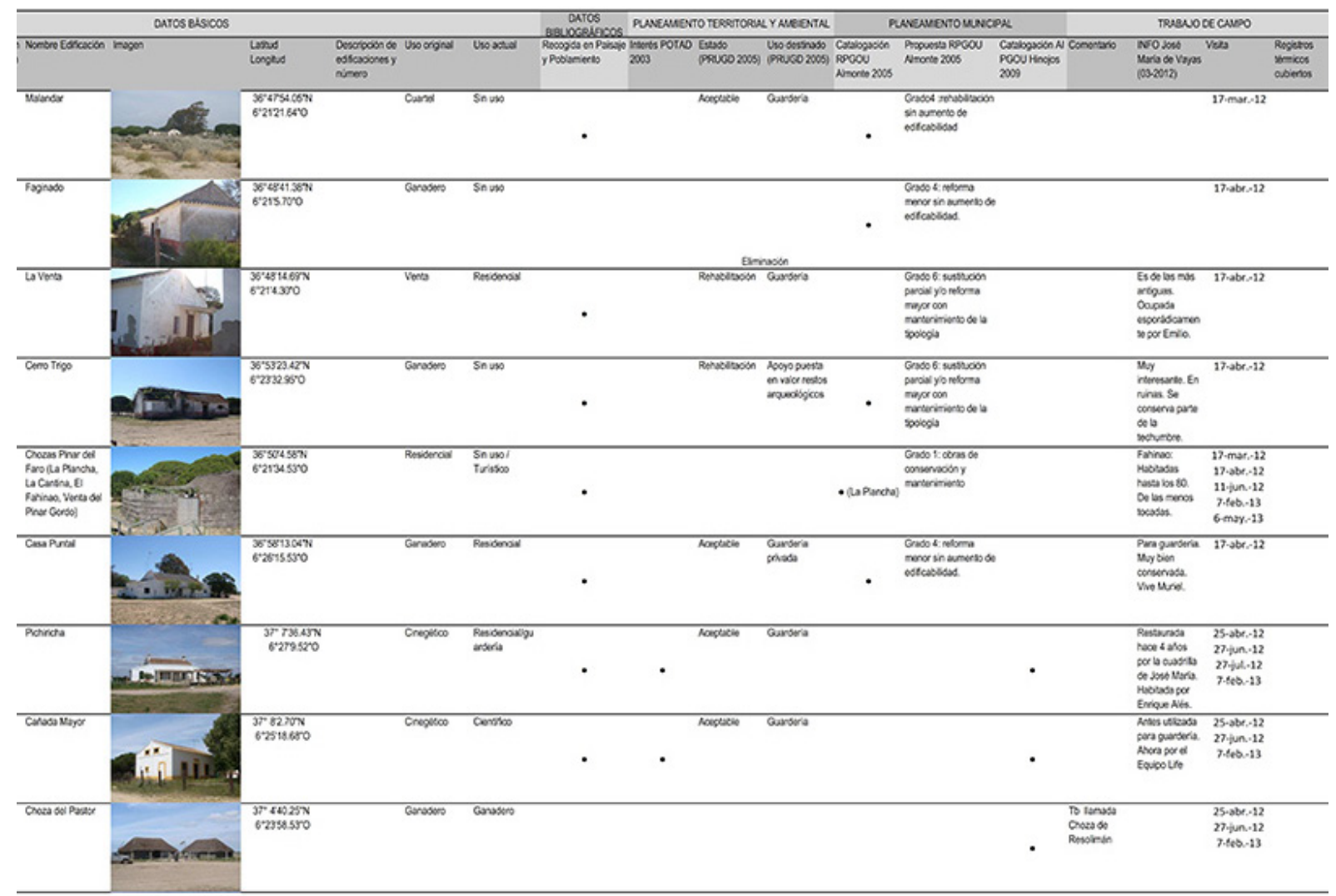

Fuente: elaboración propia. 
b) Diecisiete edificaciones se consideran recuperables.

c) Nueve edificaciones se consideran irrecuperables o en estado de ruina (aplicando para ello la definición de ruina urbanística del artículo 157 de la Ley de Ordenación Urbanística de Andalucía).

\section{ESTUDIO DE CASOS}

A la hora de seleccionar los casos finales de estudio, se ha terminado incidiendo específicamente en aquellas edificaciones que presentan rasgos autóctonos y distintivos que las singularizan dentro del conjunto de construcciones rurales andaluzas, y que más han adaptado sus configuraciones a las condiciones físicas y climáticas del lugar. Se han considerado los diversos paisajes de Doñana y las principales tipologías edificatorias dentro de la arquitectura doméstica vernácula que se da en el Parque. Se ha tenido en cuenta asimismo la facilidad de acceso y el estado de conservación y régimen de ocupación de cada edificación. De este modo, se han seleccionado hatos y chozas; se han elegido edificaciones en uso, en desuso y abandonadas en proceso de degeneración. Igualmente, se han considerado los diferentes microclimas que se encuentran en Doñana, directamente relacionados con sus distintas unidades ambientales. También es reseñable la elección de una pareja de hatos, la Casa de la Pichiricha y la Casa de la Cañada Mayor, que pertenecen a un mismo tipo constructivo pero que han sido intervenidos cada uno durante la historia en diversos grados, por lo que se estima interesante el comprobar cómo se han comportado frente a estos cambios de manera comparativa.

La Tabla 1 resume estas cuestiones e ilustra la selección de casos.

De cada uno de los casos estudiados se ha elaborado una ficha que consta de unos datos básicos (descripción, información urbanística, constructiva, datos sobre su estado actual), obtenidos a partir de una observación in situ, de información fotográfica actualizada y de levantamiento planimétrico esquemático, según datos obtenidos en las visitas de campo.

Como parte de la caracterización formal y constructiva de las edificaciones y, en la línea de analizar su adaptación al medio y su capacidad de respuesta ante él, se realizó un estudio higrotérmico que contribuyera a aclarar esta cuestión y a arrojar datos concretos de registros climáticos en el interior y en el exterior de los casos seleccionados, mediante la instalación de sondas de temperatura y humedad que midieron y registraron ambos parámetros en cuatro de las edificaciones durante un periodo de doce meses. (Figura 10 y Figura 11)

Tabla 1. Selección final de casos de estudio

\begin{tabular}{|l|l|l|l|}
\hline Edificación & Entorno & Tipología & Estado / Ocupación \\
\hline Casa de la Pichiricha & Matorral, monte bajo & Hato & En uso, habitada \\
\hline Choza del Pastor & Marisma & Choza & En uso, ocupación esporádica \\
\hline Casa de la cañada Mayor & Bosque & Hato & En uso, ocupación esporádica \\
\hline Choza en la Plancha & Bosque & Choza & En desuso. Sólo visitas esporádicas \\
\hline
\end{tabular}

Fuente: elaboración propia.

Figura 10. Casa de la Pichiricha: fachada trasera, porche delantero, estructura de cubierta

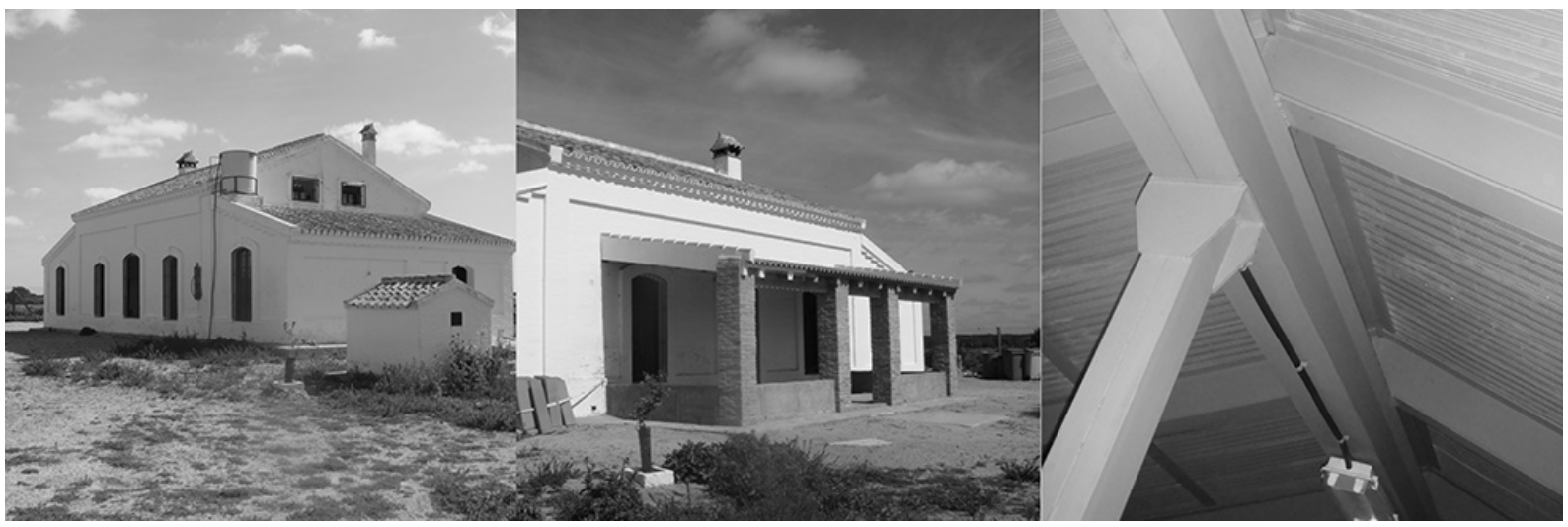

Fuente: elaboración propia. 
Figura 11. Casas de la Pichiricha y de la Cañada Mayor: esquemas de plantas y alzados
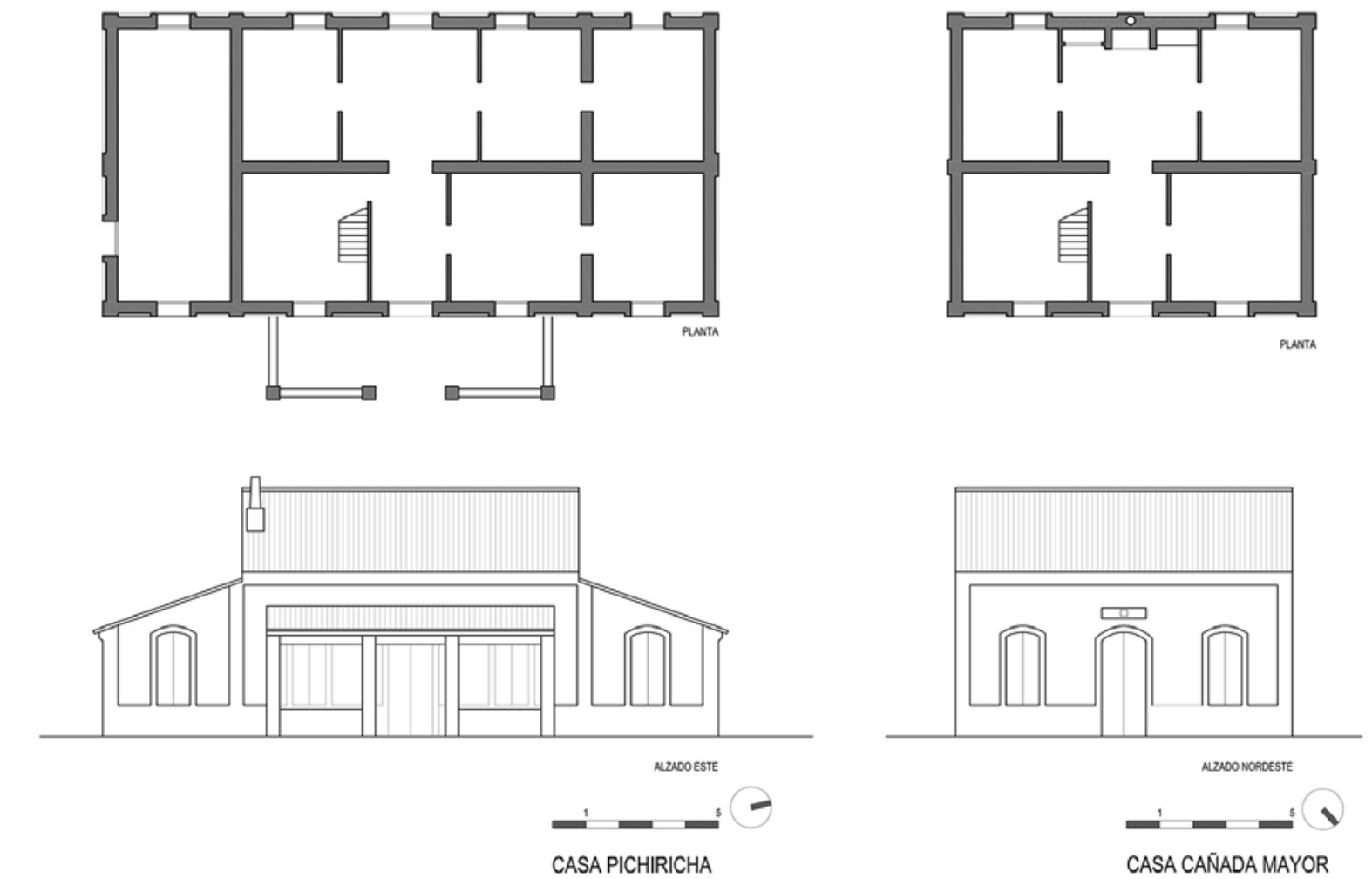

Fuente: elaboración propia.

En el caso de los dos hatos seleccionados, se han detectado en ellos las características habituales de esta tipología: la edificación principal es una construcción de estructura simple, de una sola planta, con cubierta a dos aguas de teja o fibrocemento, aunque en ambos casos se consigue un espacio adicional ocupando la planta bajo cubierta. Ambos se construyen con estructura de muros de fábrica de ladrillo. El acabado es enfoscado y pintado. Presentan dos crujías con un paso entre ambas que hace las veces de espacio central de estancia, alrededor del cual se sitúan los dormitorios. Normalmente se integra una cuadra para caballos en el mismo cuerpo edificatorio, aunque con acceso independiente desde el exterior y sin comunicación con la vivienda; esta cuadra está más dimensionada en los hatos de la marisma, por su mayor dependencia del caballo como medio de transporte. En el caso de la Casa de la Cañada Mayor no se dispone de esta estancia, y en el caso de la Casa de la Pichiricha funciona hoy como un almacén. Es frecuente en los hatos la existencia de dos puertas enfrentadas en la edificación, para posibilitar la ventilación cruzada, rasgo que solo se encuentra en la Casa de la Pichiricha.
En cuanto a la caracterización térmica, en el caso de los hatos se comprobó en su interior la atenuación de las temperaturas y de la humedad relativa registradas en el exterior, adecuándolas a los límites y estándares de confort térmico, por la propia configuración y concepción del tipo constructivo, con un buen índice de compacidad, una adecuada cultura de muros y una buena relación en sus fachadas entre huecos y macizos. (Figura 12)

Las dos chozas estudiadas ilustran la técnica constructiva habitual en este tipo de edificación y también la adaptación de la misma a los distintos ecosistemas de Doñana. El concepto constructivo es simple: se trata de una estructura de rollizos y maderas de diferentes tamaños y diámetros que forman simultáneamente la estructura vertical y de cubierta de la choza. La estructura se recubre con una gruesa capa de material vegetal, previamente recogido y dejado secar en el entorno cercano, que se compacta y se superpone en capas sucesivas, hasta alcanzar un espesor que en algunos casos es de más de $50 \mathrm{~cm}$., y que en el caso de las dos chozas analizadas se sitúa en un espesor medio de $25 \mathrm{~cm}$. De lo bien compactada que esté esa capa vegetal dependerá la impermeabilidad de la choza. Normalmente la estruc- 
Figura 12. Casa de la Cañada Mayor: vista general, detalle de acceso, estancia bajo cubierta

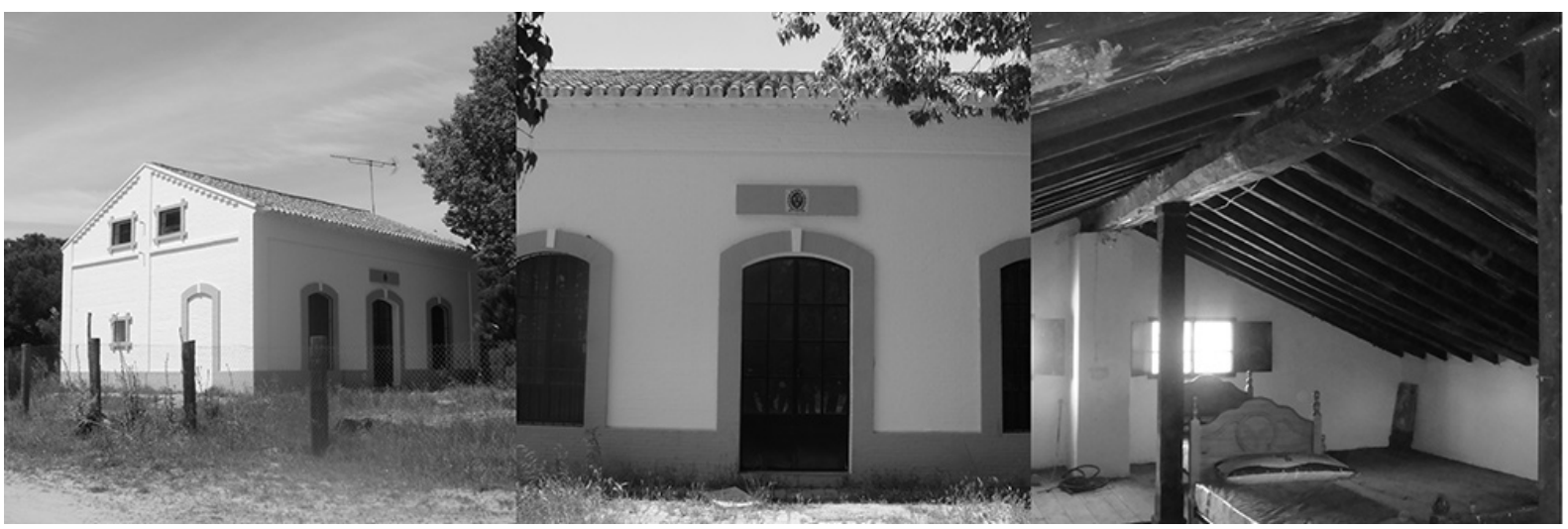

Fuente: elaboración propia.

tura solía ser de enebro o sabina, por su accesibilidad y dureza, aunque en los últimos tiempos se ha impuesto el uso del pino (principios del siglo XX) y del eucalipto, que tienen como ventaja el ser maderas más largas y resistentes a la humedad y a los insectos. Cada una de las piezas de madera empleadas recibe un nombre concreto en función de su posición en la estructura, que siempre se ha mantenido constante en los tipos observados, aunque con ligeras variaciones en los casos de las chozas de construcción más moderna. (Figura 13 y Figura 14)

En cuanto a la envolvente, el vegetal que se usa en cada caso está ligado al territorio concreto donde se asienta la choza: junco (el más usado para cubiertas), castañuela (habitual en las chozas de la marisma, como es el caso de la Choza del Pastor), brezo o barón. La hierba se siega a mediados de septiembre, con la marisma aún seca. Se agrupa en haces, que se amontonan a su vez en almiares para dejarse a secar. A la acción de cubrir la choza en sucesivas capas se le denomina cobijar. Antiguamente las capas se cosían con palmas trenzadas por el propio chocero, aunque en la actualidad se unen con cuerdas, clavos y tornillos (Cobo López y Tijera Jiménez, 2008). Con frecuencia se cubre la cumbrera con malla de gallinero, para proteger el material vegetal contra las aves, que pueden anidar en ese lugar o llevarse el vegetal, como se observa en el ejemplo de la Choza de la Plancha, que ilustra también otro gesto típico en estas construcciones, que rematan su cubierta con una cruz formada por dos palos de madera. Sin embargo, tal y como ocurre en la Choza del Pastor, en las últimas chozas ejecutadas es habitual el proteger con malla toda la choza, incluida cubierta y cerramientos completos por su capa exterior. Otra característica habitual en las últimas generaciones de habitantes de las chozas es el blanqueo de superficies y estructura interior, con intenciones higiénicas, como se ha podido comprobar en la propia Choza de la Plancha. (Figura 15)

Figura 13. Choza en La Plancha: exterior, acceso, interior

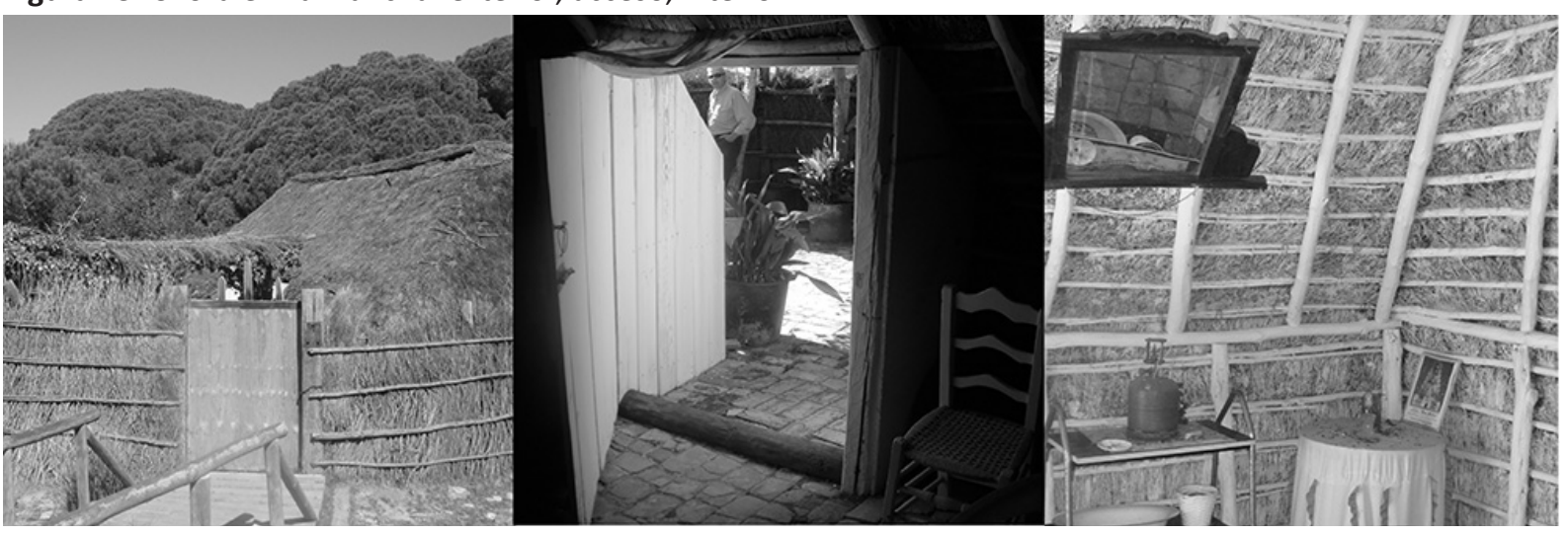

Fuente: elaboración propia. 
Figura 14. Choza del Pastor y Choza de la Plancha: esquemas de plantas
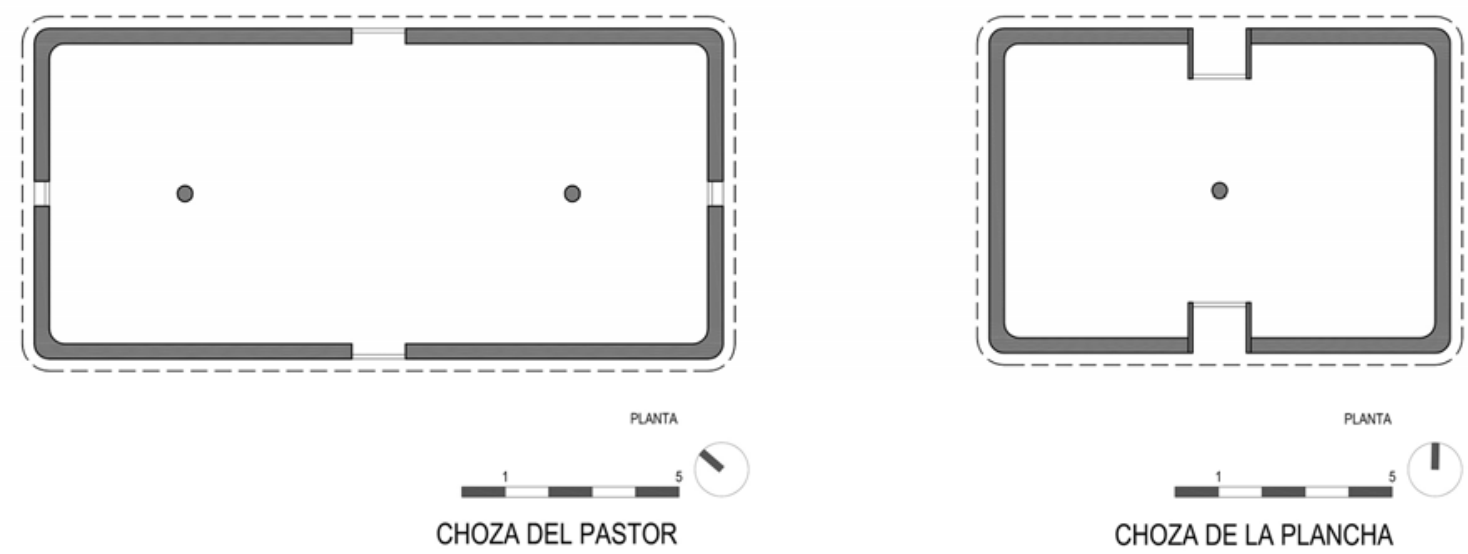

Fuente: elaboración propia.

Figura 15. Choza del Pastor: exterior, interior, estructura

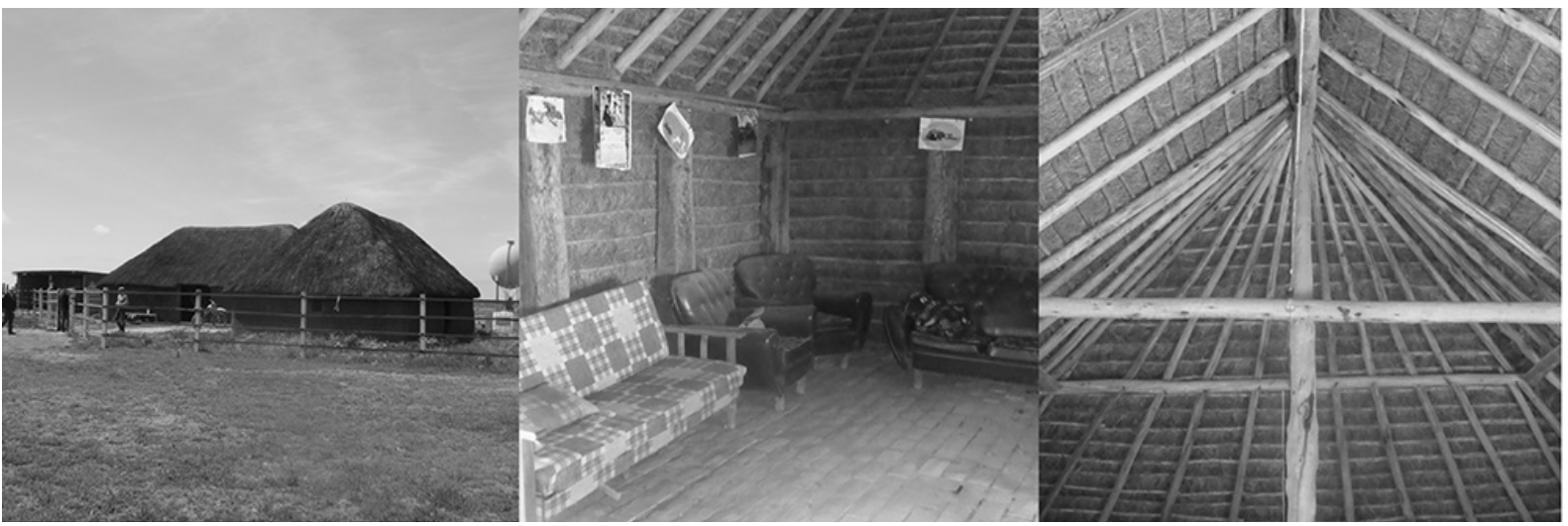

Fuente: elaboración propia.

Por último, los datos de humedad y temperatura registrados en los dos casos de chozas estudiados han permitido observar que resulta decisivo el emplazamiento de cada uno de los dos casos, reaccionando ambas chozas ante los registros más extremos de temperaturas de manera distinta en función de las características físicas del enclave concreto en el que se encuentran y siendo sensibles, por ejemplo, a la cercanía del río o a la presencia de vegetación y árboles de sombra.

\section{CONCLUSIONES}

La investigación evidencia la complejidad del campo estudiado, debido a la velocidad con la que se suceden los cambios en Doñana y a que se trata de un entorno dinámico, permanentemente en evolución. Las edificaciones se insertan en este marco complejo de manera natural; la mayor parte de las veces, surgen como respuesta humana a una necesidad derivada de un uso o un aprovechamiento del territorio. Las evoluciones y cambios en estos usos han determinado igualmente la vida de estas edificaciones, que se han visto influidas por los cambios históricos sucedidos en Doñana, fundamentalmente en materia de régimen de propiedad del suelo y de los aprovechamientos que de ellos se derivaban.

Esta inercia de cambio permanente nos ha llevado hasta un estado actual de las edificaciones en las que, como se ha comprobado, aproximadamente una quinta parte de las construcciones se encuentran irrecuperables y solo nos quedan algunos restos de ellas, con la pérdida que ello supone en cuanto a la memoria de unas épocas, unos modos de vida y unos usos humanos de los que los edificios son tes- 
tigos. Lógicamente, la pérdida y el abandono de una edificación están ligados a su desuso, por lo que el argumento del uso, que es central en el acercamiento a las edificaciones que se propone en este artículo, se convierte en una cuestión clave en el análisis de estas edificaciones y en el planteamiento de estrategias para su regeneración.

Igualmente, una cantidad importante de edificaciones se encuentran en un estado que, dependiendo de las decisiones que se tomen sobre ellas, puede ser un punto de no retorno. Según se ha expuesto, diecisiete edificaciones se hallan sin uso y en una situación en la que pueden recuperarse o continuar un inexorable proceso de degeneración y deterioro. Estas edificaciones exigen una toma rápida de decisiones, a la vez que suponen una auténtica oportunidad de ensayar una política para su recuperación. Como se ha expuesto, el planeamiento territorial y urbanístico permite intervenciones sobre estas edificaciones en diversos grados, por lo que habría que preguntarse por qué no se ha intervenido hasta el momento sobre algunas de ellas.

La caracterización constructiva y los resultados obtenidos de la instalación de sondas de temperatura y humedad ha permitido comprobar las enseñanzas que pueden obtenerse de los tipos constructivos más ligados a este territorio, como los hatos y las chozas. En primer lugar, su adaptación al medio en el que se ubican; en los hatos mediante una determinada formalización y una cierta cultura de muros; en las chozas mediante la concreción de un singular sistema constructivo que aprovecha las condiciones de la tierra y del clima, sobre todo en las chozas situadas en los pinares del río, como la analizada en la Plancha. En segundo lugar, se ha comprobado su interés y singularidad, en cuanto que son testigos de unas formas de vida y unos hábitos humanos ilustrativos de unos modos de relacionarse entre el hombre y el medio natural que ya hoy en día están prácticamente en desuso.

Se aprecia asimismo la necesidad de dar a conocer este patrimonio, que algunos de los habitantes del Parque valoran positivamente pero que no está instalado en el imaginario colectivo sobre Doñana, que reduce sus valores patrimoniales a los puramente biológicos. El conocer el patrimonio edificado, etnológico y humano de Doñana se estima como el paso previo y necesario para su valoración y para la creación de inquietudes positivas respecto a su futuro inmediato.
Dentro de este marco de análisis, resulta evidente que el futuro de las edificaciones en Doñana pasa en buena parte por mirar hacia su pasado. Como se ha expuesto, las edificaciones que han sobrevivido son las que han adaptado sus usos y sus configuraciones a las nuevas situaciones que se han ido sucediendo en Doñana; se han adaptado auténticamente al lugar y a sus exigentes circunstancias. Los ejemplos de las chozas o los hatos, que varían sus características en función de en qué ecosistema del Parque se insertan, son paradigmáticos. El caso de las chozas se convierte además en el máximo exponente de unas ciertas estrategias de eficiencia y sostenibilidad, en su adaptación al clima, en su aprovechamiento de los materiales y las formas que la naturaleza ofrece en cada zona, en su inserción en unos ciclos naturales y en unas formas de vida y oficios tradicionales que, aunque ya desaparecidos en parte, son un buen espejo en el que mirarse.

Proponemos, de este modo, algunas líneas maestras que pudieran servir para la revisión, recuperación y puesta en valor de este patrimonio edificado:

- El uso. Necesariamente, los edificios deben llenarse de contenido y funcionalidad, con usos actualizados a las nuevas necesidades de Doñana pero también con la recuperación, siempre que sea posible, de formas de vida y oficios en desuso. Se señalan a continuación algunos ejemplos:

- El uso turístico: puede ser clave en la regeneración de determinados edificios que cuentan con un especial atractivo adicional, como es el caso de la Casa del Cerro del Trigo y del yacimiento arqueológico anexo, o de las casas salineras, que podrían funcionar como elementos de interpretación del aprovechamiento salinero de la Bahía de Cádiz.

- $\quad$ El uso de guardería y científico: resulta llamativo que hasta los años 70 del siglo $X X$ se levantaran edificaciones de nueva planta en Doñana, la mayor parte de ellas sin ningún interés, y algunas de las cuales han terminado siendo abandonadas o demolidas. Los usos más asociados al corazón del Parque, como puedan ser los de guardería o los científicos, podrían aprovechar las edificaciones existentes. Los cuarteles, por ejemplo, edificaciones de mayor superficie, podrían ser sedes científicas o de laboratorios si se rehabilitaran convenientemente. 
- Otros usos tradicionales, respetando la diversidad: la mayor parte de los aprovechamientos tradicionales de Doñana son buenos para los propios ecosistemas (madereros, piñeros, ganaderos, pescadores). La conversión de este territorio en Parque Nacional ha complicado la adaptación de estos usos, exigiendo a los pocos que aún los practican una compleja tramitación administrativa, por lo que, algunos de ellos, incapaces de redactar planes técnicos, por ejemplo, terminan desistiendo; se genera además un rechazo hacia la conservación imperativa del medio natural, un medio del que ellos son auténticos defensores (Cobo López y Tijera Jiménez, 2008). El facilitar estos procesos redundaría en beneficio del mantenimiento de estos oficios y de algunas edificaciones que pudieran utilizarse de apoyo a estos aprovechamientos, como es el caso de algunas chozas o pequeños hatos. Además, implicaría a la población local en la gestión y conservación del Parque.

- No crecer físicamente sino apostar por la recuperación, el reciclaje, la reutilización. En un entorno donde la conservación de la edificación es complicada y donde existe una importante cantidad de edificaciones en desuso, parece obvio que, antes de construir de nueva planta, como se hizo hasta bien avanzado el siglo XX, es necesaria la rehabilitación y la reutilización de lo ya edificado. Es un proceso mucho más sostenible desde todos los puntos de vista, más económico, más respetuoso con el entorno y con su herencia y su historia.

- La adaptación al medio. En las intervenciones que se pudieran realizar sobre las edificaciones existentes, sería necesario ser consecuentes con su pasado, con sus formas y con sus lógicas constructivas. Esto pasa por una adaptación al entorno, tomando como ejemplo el paradigma de las chozas, sin la inclusión de materiales ni soluciones formales ajenas al medio y a lo que son los usos habituales en el Parque. Se han visto ejemplos de cómo este principio no se ha tenido en cuenta en algunos casos (edificaciones de los años 70, algunas intervenciones puntuales en los hatos); por el contrario, hay casos en que estas estrategias tradicionales de la edificación en el Parque se han aplicado con buenos resulta- dos, como el Laboratorio Luis Bolín, las variaciones contemporáneas en los tipos de choza o las utilizaciones de edificaciones de técnica mixta con cubierta vegetal.

- Políticas de sostenibilidad. Doñana tiene en sus edificaciones una oportunidad para aplicar políticas y prácticas de sostenibilidad parejas a las que se aplican en otros ámbitos de trabajo del Parque. El rescate de una arquitectura vernácula, con valores indudables, puede y debe hacerse desde un escrupuloso respeto por el medio natural y humano en el que se encuentra. La recuperación de materiales y técnicas autóctonas, la aplicación de técnicas de diseño bioclimático pasivo (como las que ya se dan en las chozas), el uso de energías renovables, etc., son aspectos que deben guiar una intervención en este tipo de edificaciones.

- Divulgación. Como se ha comentado, el patrimonio edificado de Doñana, como exponente de una cultura y de unos modos de vida, es hoy en día muy desconocido por el gran público. Su valoración pasa necesariamente por su difusión y conocimiento, por lo que sería deseable la puesta en marcha de iniciativas que contribuyeran a este extremo desde el campo investigador y académico, así como en la opinión pública, principalmente de los municipios del entorno y en su área de influencia.

El futuro de las edificaciones en Doñana debe pasar por su conocimiento, la divulgación de los valores que atesoran, y una apuesta por la regeneración de las técnicas y aprendizajes extraídos de la propia historia del lugar y de este medio natural. En palabras de Jorge Riechmann, "se trata de imitar a la naturaleza, no porque sea una maestra moral sino porque funciona" (Riechmann, 2006).

\section{AGRADECIMIENTOS}

En un marco general de colaboración entre el Máster en Ciudad y Arquitectura Sostenibles de la Universidad de Sevilla y el Espacio Natural Doñana, los autores desarrollaron una investigación que se formalizó en el Trabajo de Fin de Máster Las edificaciones en Doñana. Estrategias de eficiencia, cuya propuesta de investigación fue aprobada por la Comisión de Trabajo de Investigación del Consejo de Participación del Espacio Natural de Doñana con número de prospección 9/2012, al que agradecen enormemente los medios humanos y materiales puestos a disposición de este trabajo. 


\section{BIBLIOGRAFÍA}

Agudo Torrico, J. (1999). Arquitectura vernácula y patrimonio en Andalucía. Sevilla: Fundación Machado.

Castrillo Díaz, M. C. (2000). Doñana nombre a nombre. Estudio de la toponimia del Parque Nacional de Doñana. Huelva: Diputación Provincial.

Cobo López, M. P. y Tijera Jiménez, R. E. (2008). Etnografía de la Doñana sevillana. Sevilla: Mancomunidad de Desarrollo y Fomento del Aljarafe.

García de Alvear, M. (1986). Los ranchos de Doñana: chozas de la finca "El Pinar del Faro" del Parque Nacional de Doñana. Sevilla: Consejería de Política Territorial.

Granados Corona, M. y Ojeda Rivera, J. F. (1994). Doñana. Paisaje y poblamiento. Edificaciones en el Parque Nacional. Sevilla: Consejería de Obras Públicas y Transportes.

Fernández Alés, R y Muñoz Reinoso, J. C. (2014). Las edificaciones en áreas protegidas, ¿iincrementan la biodiversidad? EI caso del Parque Nacional de Doñana. En: Jornadas de investigación sobre la conservación de Doñana. Libro de resúmenes, Sevilla, 6 y 7 de febrero de 2014, p. 81. [En línea]. Disponible en http://www. ebd.csic.es/documents/10184/316318/ Jornadas+Do\%C3\%B1ana/3925888c4909-472e-9471-a767f8c78059

Riechmann, J. (2006). Biomímesis: ensayos sobre imitación de la naturaleza, ecosocialismo y autocontención. Madrid: Los Libros de la Catarata.

\section{Textos legales}

Ley 91/1978, de 28 de diciembre, del Parque Nacional de Doñana. Boletín Oficial del Estado no 11, de 12 de enero de 1979.

Ley $2 / 1989$, de 18 de julio, por la que se aprueba el Inventario de Espacios $\mathrm{Na}$ turales Protegidos de Andalucía y se establecen medidas adicionales para su protección. Boletín Oficial de la Junta de Andalucía no 60, de 27 de julio de 1989.

Decreto 2412/1969, de 16 de octubre, de creación del Parque Nacional de Doñana. Boletín Oficial del Estado no 257, de 27 de octubre de 1969.

Real Decreto 712/2006, de 9 de junio, por el que se amplían las funciones y servicios de la Administración del Estado traspasados a la Comunidad Autónoma de Andalucía, en materia de Conservación de la Naturaleza (Parques Nacionales de Doñana y Sierra Nevada). Boletín Oficial del Estado no 141, de 14 de junio de 2006.

Ley 8/1999, de 27 de octubre, del Espacio Natural de Doñan. Boletín Oficial de la Junta de Andalucía no 137, de 25 de noviembre de 1999.

Decreto 341/2003, de 9 de diciembre, por el que se aprueba el Plan de Ordenación del Territorio del Ámbito de Doñana y se crea su Comisión de Seguimiento. Boletín Oficial de la Junta de Andalucía no 22, de 3 de febrero de 2004.
Decreto 48/2004, de 10 de febrero, por el que se aprueba el Plan Rector de Uso y Gestión del Parque Nacional de Doñana. Boletín Oficial de la Junta de Andalucía no 44, de 4 de marzo de 2004.

Plan General de Ordenación Urbana de Almonte. Resolución de 14 de diciembre de 2007, de la Delegación Provincial de Huelva, referente al expediente CP$168 / 2001$ por la que se subsana, inscribe y publica el Plan General de Ordenación Urbanística de Almonte. Boletín Oficial de la Junta de Andalucía no 27, de 7 de febrero de 2008.

Plan General de Ordenación Urbana de Hinojos. Resolución de 11 de mayo de 2015, de la Delegación Territorial de Agricultura, Pesca y Medio Ambiente en Huelva, sobre subsanación, inscripción y publicación del cumplimiento de Resolución del PGOU del término municipal de Hinojos, aprobado por la СTOTU con fecha 12 de diciembre de 2014. Boletín Oficial de la Junta de Andalucía no 98, de 25 de mayo de 2015.

Ley $7 / 2002$, de 17 de diciembre, de Ordenación Urbanística de Andalucía. Boletín Oficial de la Junta de Andalucía no 154, de 31 de diciembre de 2002. 